\title{
AN INTERSECTIONAL ANALYSIS OF RESPONSES TO INTIMATE PARTNER VIOLENCE IN TWO MARGINALISED SOUTH AFRICAN COMMUNITIES
}

\author{
Taryn J. van Niekerk and Floretta Boonzaier
}

\begin{abstract}
This paper aims to investigate the responses available to urban and rural community members in the Western Cape Province of South Africa after witnessing, experiencing, or hearing about intimate partner violence (IPV) against women. It explores the social and material spaces that make IPV against women possible in these communities, which have a complex history of multiple forms of violence, including institutional, symbolic, and interpersonal. Seven focus group discussions with community members are analysed, using thematic narrative analysis, to explore the social and collective features of IPV and how it emerges within community responses to this violence. Constructions of IPV as an "everyday" event surfaced in the data, and mutualising language was often employed to construct IPV as a reciprocal activity with no clear distinction between attacker and victim. Also, a reconciliatory "kiss-and-make-up" narrative emerged in the data, representing how community members responded to this violence. In addition, the temporary nature of the violent event was emphasised by participants, and the aftermath was described as an opportunity for the victim and perpetrator to "reunite", thereby providing justification for non-intervention in future violent events. By asking questions about responses to IPV, this paper offers insight into, and recommendations about, key forms of community intervention and engagement for gendered violence.
\end{abstract}

Keywords: community responses, intimate partner violence, response-based approach, South Africa, thematic narrative analysis; urban and rural geographies

Taryn J. van Niekerk PhD (corresponding author) is a postdoctoral fellow in the Department of Psychology at the University of Cape Town, Private Bag X3, Rondebosch 7701, South Africa. Email: Taryn.vanniekerk@uct.ac.za

Floretta A. Boonzaier PhD is a Professor of Psychology at the University of Cape Town, Private Bag X3, Rondebosch 7701, South Africa. Email: Floretta.Boonzaier@uct.ac.za 
International Journal of Child, Youth and Family Studies (2019) 10(1): 26-48

High levels of intimate partner violence (IPV) in South Africa demand new and innovative ways of addressing and understanding the problem. IPV is a pervasive phenomenon that permeates all corners of the globe; it affects the individuals immediately impacted by the violence physically, psychologically, and emotionally, and also affects their families and communities (Butchart, Garcia-Moreno, \& Mikton, 2010).

Research on IPV, particularly from epidemiological and public health perspectives, has employed the language of cause and risk when attempting to understand the effects that IPV may have on the victims, their families, and others in the immediate environment (Hydén, Gadd, \& Wade, 2015). Although public health research on IPV has made great strides in explaining broader patterns of IPV, the full complexity of understanding IPV cannot be accounted for by a language of risk factors and cause and effect. Causal language works to diminish men's responsibility in IPV incidents by constructing the act of IPV as influenced by external forces. For example, Jewkes (2002) noted that, "Violence is frequently used to resolve a crisis of male identity, at times caused by poverty or an inability to control women" (p. 1423). Similarly, in regard to a language of risk, a statement such as, "Poverty is the exception and increases risk through effects on conflict, women's power, and male identity" (p. 1423) may have the inadvertent outcome of pathologising impoverished groups as more likely to encounter IPV and may work to decontextualise the act of IPV from the gendered and intersectional context in which it occurs. Therefore, a shift in understanding IPV against women is necessary. Responsebased work offers an alternative to understanding the experiences of those affected by IPV through asking questions about how individuals respond to this violence, and the resistance strategies available to them (Hydén et al., 2015). The social context in which IPV is located is an important site of analysis, as the conditions of those experiencing or witnessing this violence shape the kinds of responses that are possible (van Niekerk \& Boonzaier, 2015).

This paper explores the social, material, and collective spaces that make IPV against women possible, particularly in the context of communities that have a complex history of multiple forms of violence, including institutional, symbolic, and interpersonal. In addition, it asks questions about the responses available to urban and rural community members after witnessing, directly experiencing, or hearing about IPV against women. In focusing on community responses to IPV, we aim to better understand how communities make meaning of this violence, and how "victims" and "perpetrators" are represented in the South African context. It should also be noted that the use of the terms victim and perpetrator have been critiqued, particularly from a poststructuralist perspective, for their restricting categories, limiting the individual to a single aspect of identity and to the impossibility of the idea that an individual could shift between those positions (McHugh, Livingston, \& Ford, 2005). In addition, the term "victim" may suggest a positionality that invokes helplessness and passivity (Boonzaier \& de la Rey, 2003). In a similar fashion, the naming of men as "violent" draws attention to one aspect of their identity, potentially obscuring other identities that may have been more salient for both the 
International Journal of Child, Youth and Family Studies (2019) 10(1): 26-48

men and the women, as noted in Boonzaier's (2008) study. While recognising the importance of gendered power dynamics in the perpetration of IPV, we also acknowledge that these terms are not static, and therefore the terms "victim" and "perpetrator" are at times employed inside quotation marks.

Fundamentally, this paper shows that a focus on community responses to IPV shifts the lens away from constructions of violence as emergent from individual pathologies to a focus on the social and institutional mechanisms that provide sanction for the high levels of gendered violence in South Africa.

\section{Community Responses to Violence against Women in South Africa}

South Africa's history of colonisation and apartheid has produced a context in which violence has played an integral role in social relations and conflict (Vetten \& Ratele, 2013). Although the political transition that ended apartheid may have curbed the violence plaguing the country at that time, Vetten and Ratele (2013) argued that interpersonal violence, and specifically IPV, had not been similarly curtailed. Some South African research has drawn attention to the construction of masculinities, femininities, and violence, as well as to "victim" and "perpetrator" accounts of IPV (e.g., Boonzaier, 2008; Lau \& Stevens, 2012; Ragnarsson, Townsend, Thorson, Chopra, \& Ekström, 2009). This trajectory of research that contextualises IPV through gendered and sociocultural norms is well established, and acknowledges that this violence does not occur in a vacuum but that it ought to be understood within its broader context.

An emerging field of scholarship that builds on the importance of contextualisation is one that understands individual responses to IPV to be part of broader social, community, and institutional responses to this phenomenon. A recent study focusing on community responses to IPV in a working-class community in Cape Town found that negative and stigmatising community representations of victims reinforced discourses of victim-blaming and made it possible to see perpetrators as almost blameless (van Niekerk \& Boonzaier, 2015). It was also found that some survivors of IPV internalised these victim-blaming representations, which resulted in the silencing and (re)subjugation of women survivors (van Niekerk \& Boonzaier, 2015). Similarly, Boonzaier (2014) illustrated that abused women engage with and sometimes internalise circulating narratives about themselves and their positioning in violent relationships, resulting in implications for their subjective positionings and the possibilities for change that they are able to imagine and enact. The findings from the above studies provide insight into how survivors' responses to the violence perpetrated against them are shaped by community representations of "victims" and "perpetrators", as well as the material and sociocultural conditions in which they find themselves.

Coates and Wade (2015) argued that, in order to leave violent relationships, women survivors of IPV depend on positive social responses such as comfort, protection, and empowerment to "affirm the meaning of violence as wrong" (pp. 178-179). Negative responses, on the other hand, have the capacity to further harm survivors and sanction future acts of 
violence. Indeed, responses to IPV against women send messages not only to "victims" but also to "perpetrators" of this violence. These may include messages that certain behaviours and acts are permissible (Hydén et al., 2015).

Individuals' responses to IPV are additionally shaped by their geographies and the social locations in which they find themselves. Studies have drawn attention to how the geographical isolation and lack of services encountered by survivors of IPV in rural settings might exacerbate the emotional, physical, and psychological vulnerability these individuals are likely to experience (Grossman, Hinkley, Kawalski, \& Margrave, 2005; Lanier \& Maume, 2009). Furthermore, Grossman and colleagues (2005) noted that immigrant women residing in rural areas are likely to experience greater vulnerability due to intersections of geographical location and other oppressions such as race, class, and immigrant status. Although the above studies on rural and urban geographies have made some inroads into understanding individual responses to IPV in various places and spaces, Pruitt (2008) suggested that research on the perpetration of IPV still tends to assume an urban norm and positions rurality as the "other". In normalising urbanity, the social and material conditions in rural settings that make violence possible and affect the aftermath of this violence are obscured. This study situates its analysis of community responses to IPV in the context of urban and rural communities that find themselves on the socioeconomic and geographical margins. Furthermore, as the rural IPV research has been carried out predominantly in the Global North and Australia (Sandberg, 2013), we argue that this paper adds to our knowledge about IPV, and individuals' responses to it, in rural and urban communities in a Global South setting.

This paper additionally recognises that community norms, discourses, and narratives on violence may act as powerful psychological resources taken up by community members to construct and maintain personal meanings and identities (Humphreys, 2000). As a result, this work takes seriously the knowledges that communities have of IPV against women and engages with them. In addition, we ask questions about the responses available to urban and rural community members after either witnessing, directly experiencing, or hearing about IPV against women. The ways in which individuals use these community beliefs around IPV to construct personal identities is also of significance in this paper.

\section{Method}

The recognition of "place" as a social location in feminist violence research requires further development, as suggested by Sandberg (2013). Rural and urban geographies have not been central to intersectional research on IPV against women (Sandberg, 2013); therefore, our analysis of IPV against women in rural-urban settings attends to this gap by applying an intersectional approach. This approach refers to the core theoretical tenets put forward by second-wave Black feminists who posited that social identities and oppressions derived from sexuality, ethnicity, gender, class, race, disability, geography, and so forth intersect and are 
"interdependent and mutually constitutive" (Bowleg, 2008, p. 312; Collins, 2010; Crenshaw, 1994). Intersectional theory has been central to critical race studies, Black studies, and postcolonial studies and has had particular relevance in South Africa, especially in relation to race, class, and geographical positioning (Vetten \& Ratele, 2013). In this paper, we not only seek to investigate sociocultural responses to IPV but we also remain critical of systems of power, domination, "othering", and resistance embedded in such responses (Sokoloff \& DuPont, 2005). We find the intersectional approach useful in its capacity to critique the normalisation of urban settings as "modern and gender equal and as a consequence less violent" (p. 359) and the naturalisation of rural settings as traditional, backward, and patriarchal. The "diversity of ruralities" (p. 350) and urbanities is therefore acknowledged, allowing for an awareness of how power is reinforced in these classifications (Sandberg, 2013).

A qualitative research approach is employed, in which emphasis is placed upon developing an in-depth understanding of participants' subjective experiences (Willig, 2008). Much research on IPV in South Africa finds itself within the field of epidemiology and psychology, and often takes a quantitative research approach (e.g., Abrahams, Jewkes, Laubscher, \& Hoffman, 2006; Dunkle et al., 2004; Sawyer-Kurian, Wechsberg, \& Luseno, 2009). The language of risk factors and cause and effect associated with this trajectory of research may not only oversimplify the phenomenon but also obscures the gendered and intersectional context in which IPV occurs, promoting harmful ideas about victim-blaming and passivity for those experiencing violence. Rather, a critical investigation into a language of responses presents opportunities for participants to speak about forms of resistance and agency. Critical qualitative methods provide the necessary tools to ask questions about responses to IPV, allowing this violence to be understood within the social, cultural, and historical context in which it occurs (Boonzaier, 2014; van Niekerk \& Boonzaier, 2015).

\section{On the Margins: The Urban and Rural Study Settings}

This paper draws on data from two larger studies undertaken in two impoverished and historically marginalised Western Cape communities, namely a semirural area called Vlottenburg in the Stellenbosch winelands region and an urban community on the Cape Flats ${ }^{1}$ called Hanover Park. The two communities are predominantly Afrikaans-speaking. While the two townships share similarities regarding their social composition, their histories are different. Geographically situated on the Cape Flats, Hanover Park has been described as a Coloured ${ }^{2}$

\footnotetext{
${ }^{1}$ An area developed over the 1960s and 1970s in the name of the Group Areas Act of 1950, which acted as a "dumping ground" (p. 76) predominantly for the group categorised as Coloured South Africans (Jensen, 1999). These Cape Flats townships are often characterised by poverty, social disintegration, and violence.

2 "Coloured" is a racial term created during apartheid that referred to people of mixed-race origin and grouped particular South African citizens according to their skin "colour" (Hendricks, 2001; Lewis, 2001). Since the abolition of apartheid this term is still in use; however, it is predominantly conceived of as a social construction that serves particular political purposes (Hendricks, 2001). This paper refers to "Coloured" as a South African group, with histories and experiences of oppression during apartheid and in current day South Africa. It is not inferred that racial categories have any anthropological or scientific root.
} 
International Journal of Child, Youth and Family Studies (2019) 10(1): 26-48

community, located on the periphery of Cape Town and lodged within the boundaries of the Cape Town municipality. It was established in 1969 and was one of the many areas to which Black South Africans were forcibly moved as a result of the apartheid Group Areas Act of 1950 (Jensen, 1999; Lewis, 2001).

The semirural community of Vlottenburg is in many ways representative of the farming communities in the Western Cape. The majority of residents who live in Vlottenburg are farm labourers who either work on farms or live in informal settlements in the area. Harsh conditions characterise life for individuals in these areas; these include substandard housing and amenities, and high levels of poverty, ill-health, alcohol abuse, and violence. In 2011, a Human Rights Watch report illuminated some of the abuses and harsh conditions experienced by people working in the agricultural sector in the Western Cape. The report describes farm labourers as being in a precarious situation, earning the lowest wages in the country and often entangled in exploitative and paternalistic relations with farm owners (Human Rights Watch [HRW], 2011). The position of women farm workers is especially oppressive and treacherous as they are paid less than their male counterparts and face greater levels of insecurity through lack of permanent employment as well as through being placed in positions of dependence on partners who may be abusive. Migrant women farm labourers are seldom granted residence rights, although these may be granted to men labourers.

Despite their geographical disparities, both Hanover Park and Vlottenburg display many symptoms of impoverished areas through their physical environments and the high degree of social and structural disintegration. These townships are characterised by high levels of unemployment, violence, crime, and drug and alcohol abuse. In particular, through our personal observations we have noted how Hanover Park has entered public discourse in local news reports featuring gang shootings in the area, which at times have fatal outcomes for innocent bystanders.

This study situates its analysis of community responses to IPV in the context of these urban and rural communities that find themselves on the socioeconomic and geographical margins. Given that a comparative analysis of IPV in Hanover Park and Vlottenburg has not yet been carried out we aim to undertake an analysis that illustrates the kinds of responses that emerge from these contexts. Although the data used in our study were initially collected for different purposes, we find a re-analysis using a response framework useful in its capacity to foreground the social, material, and cultural contexts of rural and urban settings as important sites of analyses, as these conditions shape the kinds of responses to IPV that are possible for community members. In addition, we take this re-analysis as an opportunity to investigate the nuances unique to each community, and to offer insights into any contrasts between the rural and urban data.

\section{Sample and Data Collection Procedures}

Seven focus groups were conducted in the two communities studied, each 60 to 90 minutes long. Nineteen women participated in the Vlottenburg focus groups, and 22 women and 
International Journal of Child, Youth and Family Studies (2019) 10(1): 26-48

4 men participated in the Hanover Park groups. Focus groups were held at the local church in the Vlottenburg area and at a community organisation in the Hanover Park area.

To be considered for participation in the focus groups, community members had to be comfortable communicating in English or Afrikaans, and they had to be 18 years of age or older. In Vlottenburg, a member of the community who had been involved in assisting with previous research efforts in the area provided a convenience sample, which included only women. However, the snowball sampling method was used for the Hanover Park focus groups, which included both men and women. We thus acknowledge that the conclusions drawn about responses to IPV in the rural setting will be limited by the sample of women only.

The demographic profile of participants from both communities appeared more similar than different. Women from Vlottenburg were younger on average but participants from both communities had low levels of education and a high likelihood of being unemployed. The average age of the Vlottenburg women who participated in the groups was 33 years. Five of the 19 women $(26 \%)$ were employed, mainly in domestic work or cleaning. Some women reported having completed Grade 12, but overall low levels of education were reported, with one woman reporting no formal schooling. The average age of the Hanover Park participants was 39 years. More than $60 \%$ of the participants reported having been unemployed at the time of their participation, while just under a quarter of the sample reported being employed full-time, parttime, or in the informal sector. The remainder of the participants described themselves as pensioners, housewives, or "other". In terms of education, $85 \%$ of the participants reported not having completed secondary education.

The group discussions were semi-structured and covered the following areas: why men commit violence against female partners; how IPV affects their community; how they would define the act of abuse; where IPV normally takes place in their community; and how community members, as onlookers, respond to public or private acts of IPV against women. Opinions were often relayed in the form of personal experiences and stories, and frequently featured other members in their communities. The context of participants' storytelling was important as it was often framed by the immediate audience of focus group members and facilitators, and largely involved the co-construction of narratives amongst the focus group participants. To ensure confidentiality, pseudonyms were used and personal identifiers were removed from the data.

\section{Data Analysis}

The focus group data were analysed employing a thematic narrative analysis. A narrative approach allows for the acknowledgement that constructions of IPV in individuals' stories can be seen as grounded in the common stories contained in a particular culture or society (László, 1997). Studies have suggested that community narratives and norms act as powerful psychological resources used by community members to construct and maintain personal and collective identity (Humphreys, 2000; Stuber, 2000). The analysis is also motivated by a feminist 
poststructuralist approach, one that places emphasis on language, power, subjectivity, and the coconstruction of meaning (Weedon, 1987). In addition, we focus upon the storytelling context as it shapes what is said in the focus groups and the interactions between participants.

Our analysis was guided by Riessman's (2008) delineation of thematic narrative analysis where a focus is placed on what is said by participants, rather than how narratives are relayed. After transcription, the coding process began and was followed by the identification and refinement of themes. The themes were further analysed from a narrative approach, by acknowledging the centrality of language, subject positions, knowledge, and power in shaping responses to IPV, and the tensions, complexities, and resistance implicated in these responses. Given the centrality of power to the analysis, we offer a reading into the intersections of class, race, gender, heterosexuality, location, and other axes of power and inequality to understand how responses to IPV are forged.

\section{An Analysis of Community Narratives of IPV}

Mutualising language — as termed by Coates and Wade (2004) — was frequently employed to represent IPV as reciprocal in the focus group discussions. The labels of "victim" and "perpetrator" were often obscured as participants described why and how violence happens through talk that mutualised this violence. In addition, we found that participants' talk about incidents of IPV against women — and its aftermath - featured a narrative of "kiss and make up" that defined how community members responded to this violence. In this narrative, participants referenced IPV as a "fight" and as a "lover's quarrel", often obscuring the severity of the violence and rather emphasising the aftermath, which was described as an opportunity for the victim and perpetrator to "reunite", using sexualised references and romantic language. The temporary nature of the violent event was emphasised, and the idea that everything returns to "normal" post-event provided justification for non-intervention in future violent events. The analysis to follow aims to further explore the meaning behind these response narratives amongst community members through the following themes: alcohol as a "cause" 3 and response to violence, shock and laughter as responses to violence against women, and questions about bystander intervention. These are discussed below.

\section{Alcohol as a "Cause" and Response to Violence}

Although this paper focuses on responses to IPV rather than risk factor or causal language, participants did offer their perspectives on the "causes" of IPV in their communities

\footnotetext{
${ }^{3}$ In foregrounding the central argument in this paper around the problematics of causal language, we place this term in quotation marks to acknowledge the complexities around meaning and the implications for these socially constructed narratives. Although we are centring the meanings of IPV shared by participants, there are moments where we attempt to question and disrupt "causal" and reductionist language that serves to decontexualise IPV and that could be harmful in terms of reducing accountability when it comes to the perpetration of violence against women (see Boonzaier, 2008; Hydén, 1994; O’Neill, 1998, p. 464; Stamp \& Sabourin, 1995).
} 
and subsequently showed how these perceived "causes" framed their responses to this violence. Alcohol is present in all participants' accounts of violence in their community ${ }^{4}$, particularly with respect to IPV. Primarily, it was portrayed as a precursor to IPV: the consumption of alcohol gives men the opportunity to bring up issues or problems that may have been bothering them, as expressed in all seven focus groups. For example:

Diana: In the week he just sits and listens to what's happening. The weekend when he has a drink and then ...

Erica: ... then the whole week's stuff comes out

Diana: ... yes! Like that! (FG1; Vlottenburg)

Diana and Erica co-construct a narrative about alcohol as a gateway for their male partners to express their issues regarding the relationship, which at times led to the perpetration of violence against the women. There appears to be shared experiences where alcohol consumption was regarded as the perceived "cause" of arguments in their relationships. Qualitative research has shown that men who have perpetrated IPV under the influence of alcohol have used this as a way of justifying their violence as an uncontrollable, impulsive act (Boonzaier, 2008; Hydén, 1994; Stamp \& Sabourin, 1995). Other research shows the ways in which alcohol and other drugs may have a disinhibiting effect on the perpetration of IPV against women. Although violence may have been considered wrong when sober, when men are abusing alcohol, they may be more likely to perpetrate IPV (Jewkes, Levin, \& Penn-Kekana, 2002; Rich \& Grey, 2005; SawyerKurian et al., 2009). As well, the evidence suggests that men who have been drinking and taking drugs at the time of assault inflict more serious violence on partners (Sawyer-Kurian et al., 2009).

Alcohol was understood to be a precursor to men's violence against women partners in terms of perpetration but it also represented a precursor to women's victimisation. According to participants, when women had been drinking (with or without their partners) they were more likely to become victims of violence:

Pam: Because she was drinking with her friends, they will think, no, it's her, she's the problem, she caused it, so she can just get a hiding.

Anna: Yes.

Pam: Because she drinks. (FG2; Vlottenburg)

\footnotetext{
${ }^{4}$ The prevalence of substance use in the lives of the participants should be interpreted in its historical context. Until the 1990s when the dop-system [tot-system] was abolished, farmers compensated Black employees with alcohol in full or partial payment for their labour - a form of exploitation that still persists in some rural areas of South Africa today (Boonzaier \& van Schalkwyk, 2011; Haupt, 2001; HRW, 2011). Boonzaier and van Schalkwyk (2011) and Haupt (2001) argued that this system played a vital role in consigning communities to a cycle of social, economic, and alcohol problems.
} 
International Journal of Child, Youth and Family Studies (2019) 10(1): 26-48

The participants refer to "they" — the "other" — who respond to IPV against women through a discourse of victim blaming, thereby positioning women who drink as responsible for the abuse perpetrated against them. Pam and Anna delivered a sociocultural narrative that appeared to be a dominant discourse in their community, although it is not clear whether they too subscribed to this particular response that blames women victims of violence. Jewkes and colleagues (2002) observed in their cross-sectional study across three South African provinces that women were more likely to experience IPV if they drank alcohol and if they held liberal views on "women's roles". Furthermore, according to Ratele and colleagues (2007), young schoolboys from a township in the Western Cape drew on norms that constructed drinking as an improper behaviour for girls and women, and boys preferred girls who did not subscribe to these perceived "rough" behaviours. Women's consumption of alcohol as a precursor to their victimisation may then be interpreted within traditional gender norms of femininity. While drinking might be an acceptable and sometimes respectable activity for men, scholars have observed that it is often not regarded as acceptable for women (Campbell, 1998; Lindegaard \& Henriksen, 2009).

Narratives about alcohol consumption also allowed community members to blur the distinction between "victims" and "perpetrators". In two focus groups, Hanover Park community members mutualised violent acts between men and women partners particularly when both partners had been consuming alcohol or drugs:

Velma: You get a case where the woman is the abuser [...] you get it but it's like 10 out of 1000 .

Kim: It all depends the situations, she does it because sometimes they drink together, they drug together and so on (FG5; Hanover Park)

Matthew: It happens on a daily basis. If I go to the terminus I see guys hitting his lady there. Because they're, all of them are on drugs man [...] Daily basis.

Megan: Even if they're drinking together also. Like on the yard they're drinking and now they're getting drunk and now they perform with each other now. And they hit, the guy hit now the [woman], "you can drink like this and you drink and so" and so and so on.

Interviewer: Are they hitting each other?

Janine: No the guy hits the lady, "You can't drink any more just go home". (FG7; Hanover Park)

Participants explained that public violence between drunk or drug-abusing couples occurred on a "daily basis" in their community, with the couple "performing" with each other or the man "hitting" the woman in order to discipline her for drinking. These violent acts were constructed as mutual - particularly by Megan — in that both the man and woman often participated in drug use or drinking together in their community, and it consequently made the subject positions 
International Journal of Child, Youth and Family Studies (2019) 10(1): 26-48

of victim and perpetrator unclear in the event of violence. However, upon clarifying whether this violence that occurs between two drunken partners is in fact mutual, Janine explains in the above extract that this violence is generally one-sided, perpetrated by the man. Both Vlottenburg and Hanover Park residents appear to draw upon dominant community narratives that position women who partake in alcohol and drugs as punishable by male partners. Although the focus group participants did not explicitly align themselves with this discourse, they did not articulate their opposition to this response narrative.

While alcohol was seen as a precursor to men's violence both in terms of perpetration and women's victimisation, it was also constructed in this Vlottenburg group discussion as a way in which the violence or the harm caused by the violence can be defused:

Interviewer: What happens after he hit you?

Sophia: Then he buys us two beers and then he goes to lie down [everyone laughs]. (FG2; Vlottenburg)

The participants described how, after a violent incident, the parties would go and drink together, which implied that the conflict had been resolved. In the above extract, Sophia relays her subjective experience of the aftermath of violence against her. Wendt (2009) found that in the context of smaller rural communities, "gossip networks" might impede women from revealing their experiences of IPV or from seeking help. However, the data above show how a Vlottenburg woman, in the presence of fellow community members who may have encountered similar experiences of IPV, disclosed her experience of violence, which was followed by laughter from all participants in the group. The response of laughter or humour by the women may have offered a way of coping with the potentially negative social and community responses to women who find themselves victims of IPV. In addition, the participants' laughter could have arisen from some discomfort or embarrassment that the participants felt at what was said in the group. These narratives expressing the normalised occurrence of IPV and alcohol consumption are further unpacked in the next theme.

\section{Shock and Laughter as Responses to Violence against Women}

Across all focus groups, certain kinds of stories about violence against women provoked

strong responses of shock, dismay, and helplessness by participants, as illustrated in the Vlottenburg focus group below:

Pam: The woman is lying with a long stick inside her. I was the first person on the scene ... the woman laying ... and the stick is this long, pushed inside her [...] do you know, that woman's face is smashed in! (FG2; Vlottenburg)

Pam: Sarah's murder [...] that woman was murdered so terribly ... then we had, a week after Sarah, we had a young girl also, here in the pear orchard [...] raped and killed. And then we had another girl who went to the shop one night, nine o'clock, 
International Journal of Child, Youth and Family Studies (2019) 10(1): 26-48

seven o'clock, it's winter, never came home. The Saturday her mother looked for her, Saturday afternoon someone came to say that there's someone in the vineyards. So it was this girlie. [...] She's nine years old, laying in the vineyards, face full of cigarette holes [...] she was horribly raped, oohh!! It was heartsore. Nobody was convicted for that. (FG2; Vlottenburg)

It is notable that, although these incidents were described by one woman (who happened to be a dominant member of the group and also appeared to be an elder in the community), many of the other group participants knew about the cases she was describing and there was some contestation about the details of some of the cases. Studies on IPV in rural communities have illustrated that individuals in smaller communities can experience less privacy, which has the likely outcome of individuals' identities as the "abused" or "abuser" being revealed to others in the community (Pruitt, 2008; Wendt, 2009). Pruitt's (2008) and Wendt's (2009) findings resonate with the above extract in the way that Pam uses the first names of the victims (sometimes the perpetrators of the crimes were also known by name), illustrating that she and the other community members were not distanced from the violence. On the one hand, there appeared to be a clear sense of helplessness in the ways in which the narrating women responded to these violent acts, which was amplified in the comment at the end of the extract: "Nobody was convicted for that". On the other hand, women also responded to the violence by indicating that they were fearful about walking around in their community after dark and that they consequently restricted their movements.

IPV was seen as part of a continuum of violence in the community. In contrast to the above accounts of murder, participants represented IPV as a regular and "everyday" occurrence; narratives of IPV as a routine event were emphasised through the use of mutualising language. This is aptly illustrated across the focus groups through the ways in which the aftermath of the violent incidents was described and through the laughter that often occurred:

Pam: We argue over simple things. He pushed me and I fell, and er ... the window of his van also broke, I smashed the window of his van and then he pushed me. Okay, and then when I fell he still kicked me in the stomach. I picked up my shoe, and er, the sandal, obviously the shoe broke. And then went we went to lay, and er, the two of us were at it, then he was already very drunk. But I tell you, I took that same shoe that broke and I hit him! I hit him with that shoe. He can never hit me like that. I'm just happy that he didn't do it in front of his friends, he did it when they left. Then I told him-

Anna: - and afterwards when you were done fighting?

Pam: ... stukkie-stukkie! (Translated as "small piece-small piece" which in Afrikaans is a colloquial way of indicating that you are talking about having sexual intercourse) [Everyone laughs]. (FG2, Vlottenburg) 
International Journal of Child, Youth and Family Studies (2019) 10(1): 26-48

Marie: ... No, those two are just characters [Emma: Hmm!]

Marie: Hey, they fight now! Later then they-

Emma: — then they are lovey dovey [laughter]

Marie: Tonight they fight then they are lovey dovey again. (FG3; Vlottenburg)

In the above extracts, as well as across two focus groups conducted with Hanover Park participants, narratives on IPV appear to focus on the typical, everyday occurrence of IPV and the recurring nature of violent incidents. The aftermath of this violence was described through "kiss and make up" stories about "reuniting" in a loving or sexualised way. Moreover, in the first extract, Anna's interjection illustrates that in moving beyond the story of the violence to the aftermath where the couple "make up" by having sex, a shared understanding about how the violence unfolds is demonstrated. In addition, the specific language participants used to describe the violence is also a clear signal of how they were constructing the violence. For example, the term "fight" is frequently used in the above extracts to describe the violence, and is used to signal violence as a mutual activity. Constructing the violence as such suggests a "reciprocal activity with no clear distinction between attacker and victim" (Hydén, 1994, p. 104) and obscures the dominant-submissive relations between the partners. This mutualising language also fails to depict the unilateral nature of the violence or the victim's experience of those acts (Coates \& Wade, 2004). For example, in Coates and Wade's (2004) analysis of legal judgements and media analyses, it was found that verbal partner abuse was described as "a disagreement", while the physical assault and self-defence of the victim was rephrased as "exchanging blows". When IPV is constructed as mutual, then issues of victimhood are not clearly delineated, and blame can be placed onto the victim (Boonzaier, 2008).

While women use the term "fighting" to connote relationship violence as a mutual activity and while they also use the term "fighting" as a rhetorical device, there are instances where women clearly represent men's violence as a form of abuse against women partners. For example, "That woman gets a hiding every week" (FG2; Vlottenburg) illustrates that the woman is clearly positioned as a victim of the violence perpetrated by her male partner. The term "hiding" is more closely associated with the way in which children are physically beaten and may, therefore, provide commentary on the woman's assumed subordinate status in relation to her male partner. We argue that although participants' representations of "victim" and "perpetrator" might not always have been clearly delineated, these ambiguous references do offer insight into the complexities of "victim" and "perpetrator" positioning in the violent event, and their potential to be taken up interchangeably.

The presence of laughter and humour in the focus groups appeared to be a frequent response in the above extracts, especially to personal stories of IPV. Although this laughter might have added to the "othering" of women victims of violence, Billig (2005) and Robinson (2009) have noted that humour is also a sociocultural resource drawn upon by people to cope 
International Journal of Child, Youth and Family Studies (2019) 10(1): 26-48

with and resolve challenging situations. The act of shared laughter allows for the reinforcement of social solidarity and is sometimes employed to counter awkwardness or feelings of restrictiveness when dealing with sensitive and taboo topics (Robinson, 2009). In terms of the current data, with violence being a fairly regular occurrence (most weekends) and with the available responses to it generally having low efficacy (e.g., police response erratic and ineffective, and a lack of options for seeking outside assistance), humour may be the only resource available to help women deal with the fact that they are all potential victims of violence. However, participants seemed to regard this response of laughter as only appropriate for certain kinds of stories, such as the "kiss and make up" narrative where the violent act is constructed as reciprocal. Stories about sexual violence and femicide appeared to evoke contrasting responses of shock and fear amongst participants, indicating not only the cultural appropriateness of certain responses but also the ways in which those responses serve to reinforce the everyday position of IPV on the continuum of violence. Thus, the ways in which participants talk about violence, as illustrated above, may be a response to the "everydayness" and predictability of IPV against women that they themselves both witness and experience. The next theme notes how these constructions of IPV as an everyday, normalised event has implications for how community members respond to and intervene in this violence.

\section{Bystander Non-Intervention}

The positioning of IPV as an everyday form of violence in this study's data has implications for how community members in Vlottenburg and Hanover Park might consider responding to the violence. For example, in regard to whether a neighbour would interject or call the police when witnessing a man being violent toward his partner, participants said:

Linda: ... Look there's the law around woman abuse and you have the right to phone the police. Me as a neighbour (woman neighbour), if my (male) neighbour hits his wife then I have the right to call the police to say-

Sara: —yes but then you're in trouble the next day

Linda: ... that man can kill that woman next door [Mmmm mmm! (others interject)] ... and I did nothing. The law says that — same with the child laws if that woman abuses that child then you must call the police.

Sara: Okay, but if you do it hey, then people will turn [Linda and others: I know, I know!] ... that's what I'm saying - so people are very, you know, "must I call or not?" (FG1; Vlottenburg)

Marie: ... you know people are very funny, if you want to talk to them about things, it's not that you want to stick your nose in their business but you are trying to help. But then they want to know nothing about that problem that they have. (FG3; Vlottenburg) 
International Journal of Child, Youth and Family Studies (2019) 10(1): 26-48

The above extracts illustrate the lack of agreement in how community members narrate "appropriate" responses to IPV. Because of the frequency of occurrences of IPV and the way in which it is constructed as being normalised, community members are reluctant to intervene by calling the police. There appears to be disagreement, however, with some women indicating that it is important to intervene to end the violence but many also suggesting that the one who intervenes will become an outcast and may risk danger. The participants appear to be referencing "community codes" of loyalty, interdependence, self-sacrifice, and mutual respect for each other's "privacy". They also provide insight into how individuals are judged by their willingness to stay true to these codes of behaviour.

Whether IPV perpetration is a private or a public matter was also called into question. When community members live in very close proximity to each other (which sometimes means a lack of privacy) and IPV against women sometimes happens in the streets or in full view of other members of the community, ideas about the privacy of the family or the intimate relationship become central to why people do not intervene in others" "fights". This was particularly so in terms of public displays of IPV where Hanover Park community members also feared that becoming involved could make them targets of violence and could compromise their safety:

Megan: I don’t know if you know John? It is sad to see how he abuses his wife.

Janine: In the open air he hit her. He hit her. Then she stands with the one baby on her arm and the other one as well.

Interviewer: These things happen in public for everyone to see?

All participants: Yes!

Janine: We talk to them and then they swear at us. [Cross talk]

Matthew: Basically, it's not your business so why you want to stick your nose in their business and so if you're going to say something, then they just say, "but it's not your business, what are you looking for here" or "you don't belong here, it is me and my wife".

Janine: "It's my family".

Interviewer: Do you try to intervene?

Megan: No, never, never, never [...]

Matthew: Maybe you will get hurt, unnecessarily injured. (FG7; Hanover Park)

The participants' co-constructed narrative of public violence shows that the decision to intervene and stop the violence is complex and involves a contemplation of immediate threat. Furthermore, the Hanover Park residents appeared to be in consensus that the decision to intervene during the perpetration of domestic violence is based on the potential intervener's assessment of harmful 
risk, especially where the privacy of married relationships or family is concerned. The danger of harm to witnesses who intervene should not be underestimated in contexts such as Hanover Park, where gang involvement and interpersonal violence is a reality for many. Megan continued narrating about the tendency of couples to thwart any intervention by bystanders:

Megan: I once tried to stop a fight between girlfriend and boyfriend, then they told me "Yes, shut up, this isn't your business and do not get involved because I don't tell you what to do". (FG3; Hanover Park)

It was noted across three Hanover Park focus groups that participants' narratives about couples who responded by hindering interventions used mutualising language (i.e., "they" and "fight"). These mutualising narratives were also called upon to ambiguously contend that both parties (the man and the woman) object to this "interference": "They don't like people to ... interfere ... because then they get more aggressive" (FG4; Hanover Park). Dominant narratives circulated across these focus groups about limited intervention in violent incidents involving married couples as this was perceived as an even bigger intrusion on privacy than if the couple weren't married (Matthew: "you don't belong here, it is me and my wife"; Janine: "It's my family").

In many ways, the findings noted in rural IPV research resonate with the data emerging from both Vlottenburg and Hanover Park. In researching the support networks of rural women who experienced IPV, Bosch and Bergen (2006) found that social networks that were supportive for some life events were likely to respond unsupportively in cases of IPV as this issue was considered taboo in the community. Nonsupportive networks kept women in abusive relationships and obstructed women's help-seeking behaviours (Bosch \& Bergen, 2006). Similarly, the findings that emerge from the present study suggest that community members who often know the "violent couple" personally are unlikely to intervene and respond supportively in incidents of IPV. Although scholars such as Grossman and colleagues (2005) have pointed out that, in contrast to those residing in urban contexts, rural victims of IPV are often more geographically isolated and well known in their smaller communities, our findings illustrate strong similarities between the marginalised communities of Hanover Park and Vlottenburg in terms of the blurred private and public divide and the associated impact on responses from community bystanders. The data illustrate that, despite their disparate geographical locations, Hanover Park and Vlottenburg residents express similarities in their narratives with regard to responses to IPV and with regard to the ways that social, cultural, and material conditions intersect to allow for the particular experiences of and encounters with IPV in their communities.

Furthermore, although community members respond to IPV as something they should not interfere in (i.e., as "other people's business"), some participants clearly recognise violence as being unacceptable, leading to the expressed disagreement around non-intervention: 
International Journal of Child, Youth and Family Studies (2019) 10(1): 26-48

Emma: And then he does it sometimes with the child on the arm, if she sits with the child. We sat there then he does it with the child on the arm, then he hits her in her face, with the child on her arm. That's not right. I say, we don't interfere in their marriage, but when I see what he does, it is wrong. (FG3; Vlottenburg)

Emma responds with contestation to the dominant narrative of non-intervention. She explicitly expresses an instance where she feels most conflicted about not interfering: when a child is present during the violent incident and in harm's way. There were very few examples in the data where participants conveyed this kind of narrative of being at odds with how to respond to IPV and few exceptions to the community code of non-interference. This theme shows how justification for non-intervention through mutualising language and through "kiss and make up" narratives works to understate a victim's experience of IPV. It could also be that there is an assumption that help is always available to victims; however, the findings of this study suggest that fear silences bystanders, limiting possibilities for immediate social responses to IPV. The implications of these response narratives are further examined as we offer recommendations for future research.

\section{Recommendations and Conclusions}

We investigated community responses to IPV against women in two marginalised communities in the Western Cape Province of South Africa, using an intersectional approach. This study was largely motivated by the need to study the social and collective features of IPV against women in the South African context. In Hanover Park and Vlottenburg community members' response narratives to IPV, the "everydayness" of this violence was expressed through "kiss and make up" narratives and, at times, through the participants' laughter. This response of laughter appeared to be regarded as "appropriate" in the case of "kiss and make up" narratives, whereas stories about sexual violence and femicide evoked contrasting responses of shock and fear. This contrast in participants' responses indicates not only the cultural appropriateness of certain responses but also the ways in which the everyday position of IPV on the continuum of violence is reinforced. In providing narratives about the habitual, routine practice of IPV perpetration, we argue that the seriousness of this violence is silenced at the community level; therefore, responses to this violence are similarly shifted to reflect these representations of IPV. Violence against women (both intimate and public) is a problem in the communities studied, yet it is not clearly articulated as one of the more serious problems facing these communities. The findings reported here appear to be consistent with work done on battered women of colour in the United States, where domestic violence is seen as less serious than other problems people face in their communities, such as poverty, racism, and crime (Richie \& Kanuha, 1997).

In addition, the complexities of "victim" and "perpetrator" identities were illustrated in how these subject positions could change from situation to situation. The use of mutualising language by participants furthermore reinforced this notion of indistinct "victim" and 
"perpetrator" positionings. Symbolic violence emerges within a relationship of domination and often does not have a clear "perpetrator" and "victim", making it difficult to spot this violence (Bourdieu, 2001). Furthermore, an intersectional approach also allowed for the symbolic violence of societal exclusion and inclusion to emerge more clearly in the investigation of sociocultural responses to violence against women in urban and rural communities. The symbolic violence of which some women in the communities of Vlottenburg and Hanover Park appear to be victims occurs within a complex system of patriarchy.

Community interventions aiming to address and end IPV against women must take into account community responses to IPV. An important impact of this work will be to use the knowledge gained about community responses to improve how we intervene in IPV cases. Programmes for perpetrators and survivors of violence frequently employ models that have been developed in the Anglo-American context, with limited applicability in the local context where our study took place. These models work with survivors and perpetrators on an individual basis, largely removed from their social networks and, in particular, communities. In the design of prevention programmes and interventions for survivors and perpetrators, community organisations can draw on our findings to take full account of the social mechanisms and responses that may maintain violence or counteract it.

We show the importance of engaging with rural and urban dynamics in terms of questions around power and inequality. Dominant community narratives about IPV emerged similarly in both the Hanover Park and the Vlottenburg focus groups, signalling that the social, cultural, and material dynamics intersect to make experiences of IPV similar in these communities. Although Hanover Park can be characterised as an urban community, it may overlap with rurality in many ways, including: its position on the Cape Flats, which is distanced from the privileged centre; its limited access to services; and its being a smaller community. Findings from this study show strong similarities in how IPV is experienced in the urban and rural settings under investigation, and further research should continue these qualitative investigations into community responses across various urban and rural settings in South Africa and other Global South contexts to explore the potential for varied outcomes. Furthermore, future research might benefit by furthering the intersectional approach and asking questions about IPV in rural and urban settings focusing on the interplay between race, class, and poverty and how this impacts the prevention of and intervention in IPV.

This study shows how a focus on responses to violence shifts the lens from individual "perpetrators" and "victims" by focusing on the knowledges that communities have about IPV against women and how they shape the kinds of responses that are possible. The continuation and replication of this research will make important advances to our understanding of why, when, and how this violence continues to happen, and the kinds of responses that may be necessary for it to cease. Following this line of research will complicate our understandings of individual risk or protective factors by showing how these play out in the context of particular communities. 
International Journal of Child, Youth and Family Studies (2019) 10(1): 26-48

\section{References}

Abrahams, N., Jewkes, R., Laubscher, R., \& Hoffman, M. (2006). Intimate partner violence: Prevalence and risk factors for men in Cape Town, South Africa. Violence and Victims, 21, 247-264. doi:10.1891/088667006780644271

Billig, M. (2005). Laughter and ridicule: Towards a social critique of humour. London, UK: Sage.

Boonzaier, F. (2008). "If the man says you must sit, then you must sit": The relational construction of woman abuse: Gender subjectivity and violence. Feminism and Psychology, 18, 183-206. doi:10.1177/0959353507088266

Boonzaier, F. (2014). Talking against dominance. South African women resisting dominant discourse in narratives of violence. In S. McKenzie-Mohr \& M. N. Lafrance (Eds.), Women voicing resistance: Discursive and narrative explorations (pp. 102-120). London, UK: Routledge. doi:10.4324/9780203094365

Boonzaier, F., \& de La Rey, C. (2003). “He's a man, and I'm a woman”: Cultural constructions of masculinity and femininity in South African women's narratives of violence. Violence Against Women, 9(8), 1003-1029. doi:10.1177/1077801203255133

Boonzaier, F. A., \& van Schalkwyk, S. (2011). Narrative possibilities: Poor women of color and the complexities of intimate partner violence. Violence Against Women, 17(2), 267-286. doi: $10.1177 / 1077801210397796$

Bosch, K., \& Bergen, M. B. (2006). The influence of supportive and nonsupportive persons in helping rural women in abusive partner relationships become free from abuse. Journal of Family Violence, 21, 311-320. doi:10.1007/s10896-006-9027-1

Bourdieu, P. (2001). Masculine domination. Stanford, CA: Stanford University Press.

Bowleg, L. (2008). When Black + Lesbian + Woman $\neq$ Black Lesbian Woman: The methodological challenges of qualitative and quantitative intersectionality research. Sex Roles, 59, 312-325. doi:10.1007/s11199-008-9400-z

Butchart, A., Garcia-Moreno, C., \& Mikton, C. (2010). Preventing intimate partner and sexual violence against women: Taking action and generating evidence. Geneva, Switzerland: World Health Organisation.

Campbell, C. (1998). Representations of gender, respectability and commercial sex in the shadow of AIDS: A South African case study. Social Science Information, 37(4), 687-707. doi:10.1177/053901898037004007 
International Journal of Child, Youth and Family Studies (2019) 10(1): 26-48

Coates, L., \& Wade, A. (2004). Telling it like it isn't': Obscuring perpetrator responsibility for violent crime. Discourse \& Society, 15(5), 499-526. doi:10.1177/0957926504045031

Coates, L., \& Wade, A. (2015). 'We're in the $21^{\text {st }}$ century after all': Analysis of social responses in individual support and institutional reform. In M. Hydén, D. Gadd, \& A. Wade (Eds.), Response based approaches to the study of interpersonal violence (pp. 176-195). London, UK: Palgrave Macmillan.

Collins, P. H. (2010). Blackfeminist thought: Knowledge, consciousness and the politics of empowerment (2nd ed.). New York, NY: Routledge.

Crenshaw, K. (1994). Mapping the margins: Intersectionality, identity politics, and violence against women of color. In M. A. Fineman \& R. Mykitiuk (Eds.), The public nature of private violence (pp. 93-118). New York, NY: Routledge.

Dunkle, K. L., Jewkes, R. K., Brown, H. C., Yoshihama, M., Gray, G. E., McIntyre, J. A., \& Harlow, S. D. (2004). Prevalence and patterns of gender-based violence and revictimization among women attending antenatal clinics in Soweto, South Africa. American Journal of Epidemiology, 160(3), 230-239. doi:10.1093/aje/kwh194

Grossman, S. F., Hinkley, S., Kawalski, A., \& Margrave, C. (2005). Rural versus urban victims of violence: The interplay of race and region. Journal of Family Violence, 20, 71-81. doi:10.1007/s10896-005-3170-y

Haupt, A. (2001). Black thing: Hip-hop nationalism, 'race' and gender in Prophets of da City and Brasse vannie Kaap. In Z. Erasmus (Ed.), Coloured by history, shaped by place: New perspectives on coloured identities in Cape Town (pp. 173-191). Cape Town, South Africa: Kwela Books and South African History Online.

Hendricks, C. (2001). 'Ominous' liaisons: Tracing the interface between 'race' and sex at the Cape. In Z. Erasmus (Ed.), Coloured by history, shaped by place: New perspectives on coloured identities in Cape Town (pp. 29-44). Cape Town, South Africa: Kwela Books and South African History Online.

Humphreys, K. (2000). Community narratives and personal stories in Alcoholics Anonymous. Journal of Community of Psychology, 28(5), 495-506. doi:10.1002/15206629(200009)28\%3A5<495\%3A\%3AAID-JCOP3>3.0.CO\%3B2-W

Human Rights Watch. (2011). Ripe with abuse. Human rights conditions in South Africa's fruit and wine industries. New York, NY: Human Rights Watch.

Hydén, M. (1994). Women battering as a marital act: The construction of a violent marriage. Oslo, Norway: Scandinavian University Press. 
International Journal of Child, Youth and Family Studies (2019) 10(1): 26-48

Hydén, M., Gadd, D., \& Wade, A. (2015). Introduction to response based approaches to the study of interpersonal violence. In M. Hydén, D. Gadd \& A. Wade (Eds.), Response based approaches to the study of interpersonal violence (pp. 1 -16). United Kingdom: Palgrave Macmillan. doi:10.1057/9781137409546_1

Jensen, S. (1999). Discourses of violence: Coping with violence on the Cape Flats. Social Dynamics, 25(2), 75-97. doi:10.1080/02533959908458676

Jewkes, R. (2002). Intimate partner violence: Causes and prevention. The Lancet, 359, 14231429. doi:10.1016/S0140-6736(02)08357-5

Jewkes, R., Levin, J., \& Penn-Kekana, L. (2002). Risk factors for domestic violence: Findings from a South African cross-sectional study. Social Science \& Medicine, 55, 1603-1617. doi:10.1016/S0277-9536(01)00294-5

Lanier, C., \& Maume, M. O. (2009). Intimate partner violence and social isolation across the rural/urban divide. Violence Against Women, 15, 1311-1330. doi:10.1177/1077801209346711

László, J. (1997). Narrative organisation of social representation. Papers on Social Representations, 6(2), 155-172.

Lau, U., \& Stevens, G. (2012). Textual transformations of subjectivity in men's talk of genderbased violence. Feminism \& Psychology, 22(4), 1-20. doi:10.1177/0959353511434416

Lewis, D. (2001). Writing hybrid selves: Richard Rive and Zoë Wicomb. In Z. Erasmus (Ed.), Coloured by history, shaped by place: New perspectives on coloured identities in Cape Town (pp. 131-158). Cape Town, South Africa: Kwela Books and South African History Online.

Lindegaard, M. R., \& Henriksen, A. (2009). Sexually active virgins: Negotiating adolescent femininity, colour and safety in Cape Town. In H. Donnan \& F. Magowan (Eds.), Transgressive sex: Subversion and control in erotic encounters, (pp. 25-45). New York, NY: Berghahn Books.

McHugh, M. C., Livingston, N. A., \& Ford, A. (2005). A postmodern approach to women's use of violence: Developing multiple and complex conceptualizations. Psychology of Women Quarterly, 29(3), 323-336. doi:10.1111/j.1471-6402.2005.00226.x

O'Neill, D. (1998). A post-structuralist review of the theoretical literature surrounding wife abuse. Violence Against Women, 4, 457-491. doi:10.1177/1077801298004004005

Pruitt, L. R. (2008). Place matters: Domestic violence and rural difference. Wisconsin Journal of Law, Gender \& Society, 23, 347-414. 
International Journal of Child, Youth and Family Studies (2019) 10(1): 26-48

Ragnarsson, A., Townsend, L., Thorson, A., Chopra, M., \& Ekström, A. M. (2009). Social networks and concurrent sexual relationships - A qualitative study among men in an urban South African community. AIDS Care, 21(10), 1253-1258. doi:10.1080/09540120902814361

Ratele, K., Fouten, E., Shefer, T., Strebel, A., Shabalala, N. \& Buikema, R. (2007). 'Moffies, jock and cool guys': Boys' accounts of masculinity and their resistance in context. In T. Shefer, K. Ratele, A. Strebel, N. Shabalala, \& R. Buikema (Eds.), From boys to men: Social constructions of masculinity in contemporary society (pp. 112-127). Lansdowne, South Africa: UCT Press.

Rich, J. A., \& Grey, C. M. (2005). Pathways to recurrent trauma among young Black men: Traumatic stress, substance use, and the "code of the street". Public Health Matters, 95(5), 816-826. doi:10.2105/AJPH.2004.044560

Richie, B., \& Kanuha, V. (1997). Battered women of colour in public health care systems. In M. Zinn, P. Hondagneu-Sokelo, \& M. Messner (Eds.), Through the prism of difference: Readings on sex and gender (pp. 121-129). Boston, MA: Allyn and Bacon.

Riessman, C. K. (2008). Narrative methods for the human sciences. Thousand Oaks, CA: Sage.

Robinson, J. (2009). Laughter and forgetting: Using focus groups to discuss smoking and motherhood in low-income areas in the UK. International Journal of Qualitative Studies in Education, 22(3), 263-278.doi:10.1080/09518390902835421

Sandberg, L. (2013). Backward, dumb, and violent hillbillies? Rural geographies and intersectional studies on intimate partner violence. Journal of Women and Social Work, 28(4), 350-365. doi:10.1177/0886109913504153

Sawyer-Kurian, K. M., Wechsberg, W. M., \& Luseno, W. K. (2009). Exploring the differences and similarities between black/African and coloured men regarding violence against women, substance abuse, and HIV risks in Cape Town, South Africa. Psychology of Men \& Masculinity, 10, 13-29. doi:10.1037/a0013267

Sokoloff, N. J., \& Dupont, I. (2005). Domestic violence at the intersections of race, class, and gender: Challenges and contributions to understanding violence against marginalized women in diverse communities. Violence Against Women, 11(38), 38-64. doi:10.1177/1077801204271476

Stamp, G. H., \& Sabourin, T. C. (1995). Accounting for violence: An analysis of male spousal abuse narratives. Journal of Applied Communication Research, 23, 284-307. doi:10.1080/00909889509365432 
International Journal of Child, Youth and Family Studies (2019) 10(1): 26-48

Stuber, S. C. (2000). The interposition of personal life stories and community narratives in a Roman Catholic religious community. Journal of Community Psychology, 28(5), 507-515. doi:10.1002/1520-6629(200009)28:5<507::AID-JCOP4>3.0.CO;2-G

Van Niekerk, T., \& Boonzaier, F. (2015). Rules and representations: Social networks' responses to men's violence against women in South Africa. In M. Hydén, D. Gadd, \& A. Wade (Eds.), Response based approaches to the study of interpersonal violence (pp. 56-76). UK: Palgrave Macmillan.

Vetten, L., \& Ratele, K. (2013). Men and violence. Agenda: Empowering women for gender equity, 27(1), 4-11. doi:10.1080/10130950.2013.813769

Weedon, C. (1987). Feminist practice and poststructuralist theory. Oxford, UK: Basil Blackwell.

Wendt, S. (2009). Constructions of local culture and impacts on domestic violence in an Australian rural community. Journal of Rural Studies, 25, 175-184. doi:10.1016/j.jrurstud.2008.11.001

Willig, C. (2008). Introducing qualitative research in psychology: Adventures in theory and method (2nd ed.). Maidenhead, England: Open University Press. 